\title{
An interpretation of the elevation of serum alkaline phosphatase in disease
}

\author{
P. G. HILL AND H. G. SAMMONS
}

From the Department of Pathology, East Birmingham Hospital, Bordesley Green East, Birmingham

SYNOPSIS Evidence is presented in this paper which supports the hepatogenic theory for the mechanism by which the level of serum alkaline phosphatase is raised in liver disease and provides $\dot{\sim}$ additional evidence that serum phosphatase is not excreted in the bile. By starch gel and paper electrophoresis the normal serum alkaline phosphatase isoenzyme is shown to be rarely present in hepatic bile. The action of neuraminidase demonstrates that $\beta$-globulin isoenzymes of liver and bone are not identical. From these results a theory which clarifies the rationale of the elevation of alkaline phosphatase in bone and liver disease is postulated. The proposed mechanism may be summarized as follows. The normal serum level is the result of two factors, the rate of release of the enzyme from the tissues, principally liver and bone, and the rate of inactivation of the enzymes in the serum and body protein pool. In osteoblastic bone disease the elevated level is due to the rate of release of the enzyme exceeding the rate of inactivation. The raised level does not indicate an inability of the liver to excrete the enzyme via the biliary tract. In liver disease the increase in serum levels is a result of increased liberation of the enzyme from the sinusoidal surface of the liver cell and of regurgitation of the biliary isoenzyme back into the serum.

The origin of the elevated serum alkaline phosphatase level(AP) which occurs in obstructive hepatobiliary disease and the mechanism of its elevation have been the subjects of discussion and controversy for several decades. Opinion is divided between the proponents of the retention theory and supporters of the hepatogenic theory. The former propose that failure of the liver to excrete bone alkaline phosphatase in hepatobiliary obstruction is the major factor in the elevation of the serum level of the enzyme (Gutman, 1959; Wilkinson, 1962). The hepatogenic theory postulates that in extrahepatic or intrahepatic obstruction the alkaline phosphatase produced by the liver is unable to pass down the biliary tract and is forced back with the bilirubin into the serum.

\section{METHODS AND MATERIALS}

STARCH GEL ELECTROPHORESIS The commercially available Eel electrophoresis apparatus was used for horizontal starch gel electrophoresis following the principles of Smithies (1955). The gel buffer and electrode compartment buffer were $0.076 \mathrm{M}$ Tris (hydroxy-methyl)amino-methane and $0.005 \mathrm{M}$ citric acid, $p \mathrm{H} \mathrm{8.6}$. The

Received for publication 12 January 1967. bridge buffer was $0.3 \mathrm{M}$ boric acid and $0.06 \mathrm{M}$ sodium hydroxide, $p \mathrm{H} \mathrm{8.6.} \mathrm{The} \mathrm{gels} \mathrm{were} \mathrm{prepared} \mathrm{as} \mathrm{described}$ by Smith (1960). Electrophoresis was carried out at room temperature for three and a half hours with the power supply set at 225 volts. The initial current was 11 mAmps per gel but this rapidly dropped and stabilized at $6 \mathrm{mAmps}$ per gel. After electrophoresis the gels were sliced in half horizontally; the top slice was used for protein staining and the bottom half for localization of alkaline phosphatase.

The gels were stained for protein as described by Smith (1960).

Alkaline phosphatase was localized by two techniques: qualitatively, using a 'substrate-staining technique,' and quantitatively by estimating enzyme activity in consecutive gel segments.

QUALITATIVE METHOD The method used was a modification of the methods of Taswell and Jeffers (1963) and Kind (1958). The gel slice was covered with buffered substrate and incubated in the dark for two hours. During this time the buffered substrate solution was changed three times to minimize background staining of the gel. A Tris-maleate buffer was used (Taswell and Jeffers, 1963). The buffered substrate consisted of $50 \mathrm{ml}$. of the buffer in which was dissolved sodium $a$-naphthyl phosphate $(20 \mathrm{mg}$.). This solution was poured on to the gel slice contained in a shallow tray. Diazonium salt 654 
of o-dianisidine $(25 \mathrm{mg}$.) was dissolved in about $2 \mathrm{ml}$. of distilled water and then added to the mixture in the tray. At the end of the incubation time the gels were rinsed with water. The position of the enzyme was then visible as a purple zone.

QUANTITATIVE METHOD Alkaline phosphatase activity was measured in consecutive gel segments by a technique similar to those used by Kowlessar Pert, Haeffner, and Sleisenger (1959) and Hodson, Latner, and Raine (1962). Phenol liberated from a buffered disodium phenyl phosphate substrate was measured by the method of Roos (1963).

PAPER ELECTROPHORESIS The Eel electrophoresis equipment was used for paper electrophoresis, with Whatman paper no. $1,34 \times 5 \mathrm{~cm}$. Electrophoresis was carried out in duplicate for 16 hours at 2 mAmps per strip using $p \mathrm{H} 8.6$ Oxoid buffer, ionic strength 0.05 . One strip was stained for protein using lissamine green and the other was used to localize alkaline phosphatase by a technique similar to that used for the starch gels.

EFFECT OF NEURAMINIDASE ON BONE AND LIVER PHOSPHATASES A buffer solution was prepared as described by Robinson and Pierce (1964). Neuraminidase (British Drug Houses Limited, Dorset), 500 units/ml., was diluted 1 in 10 with the above buffer. To each $0.25 \mathrm{ml}$. portion of serum or tissue extract was added $0.1 \mathrm{ml}$. diluted neuraminidase and $0.65 \mathrm{ml}$. buffer. Controls were prepared in which the neuraminidase was replaced by enzyme which had been heated for one hour at $60^{\circ} \mathrm{C}$. The mixtures were incubated at $37^{\circ} \mathrm{C}$. for three hours after which time horizontal starch gel electrophoresis was carried out. The gels were stained for protein and alkaline phosphatase as described earlier.

SPECIMENS Alkaline phosphatase isoenzyme patterns were obtained using serum from laboratory personnel, from patients with raised levels due to bone or liver disease, and from bile and serum from patients with T-tube drainage of the common bile duct after cholecystectomy. This last group was used to make a direct comparison between the isoenzyme patterns from the two sources in the same patient.

The bone and liver extracts for the neuraminidase studies were prepared as follows. A section of femur $(18 \mathrm{~g}$.$) was sawn into small pieces and together with$ the sawdust left to stand with $20 \mathrm{ml}$. distilled water at $4^{\circ} \mathrm{C}$. for three days. It was then filtered on a Buchner funnel. Liver tissue $(17 \mathrm{~g}$.) was ground, using a pestle and mortar, with $40 \mathrm{ml}$. distilled water. It was then filtered on a Buchner funnel. The extracts were then adjusted by concentration or dilution so that the activity of alkaline phosphatase was approximately 35 KingKind units $/ 100 \mathrm{ml}$.

RESULTS

QUALITATIVE METHOD FOR STARCH GEL ELECTROPHORESIS Serum from each of the 15 normal sub- jects showed a band of activity migrating in the $\beta$ globulin region. Six of them had a second band, staining less intensely, in a position corresponding to the $\alpha \beta$-region.

In serum from nine patients with obstructive hepatobiliary disease four isoenzyme patterns were observed. Consistent findings were markedly increased enzyme activity at the anodic edge of the origin, and an elevated $\beta$-globulin isoenzyme.

The major band of activity in serum from four subjects with raised serum bone alkaline phosphatase was in the $\beta$-globulin region; a second band was present in the $\beta$-lipoprotein region. Three of the patients were adults with bone disease, the fourth was a normal child, aged 6 years.

The major band of activity in all specimens of bile from seven patients after cholecystectomy was at the anodic edge of the origin. In three of them a second band of lower activity was observed in the position of the serum $\alpha \beta$-isoenzyme. In one other patient, minor zones of activity in the $\beta$-lipoprotein and $\beta$-globulin regions were observed. Five patients showed a serum isoenzyme pattern similar to that found in normal subjects. The other two patients showed an increased band of activity at the origin although the serum alkaline phosphatase concentration was within the normal range.

QUANTITATIVE METHOD FOR STARCH GEL ELECTROPHORESIS The major band of activity in normal serum was in the $\beta$-globulin region. In two cases of four, very slight activity was also observed at the origin.

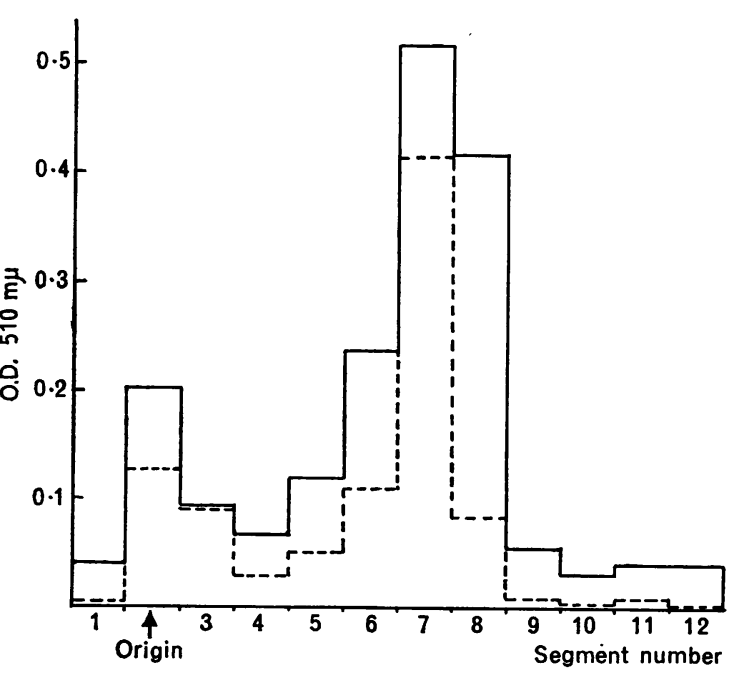

FIG. 1. Quantitative localization of serum alkaline phosphatase in two patients with liver disease. 


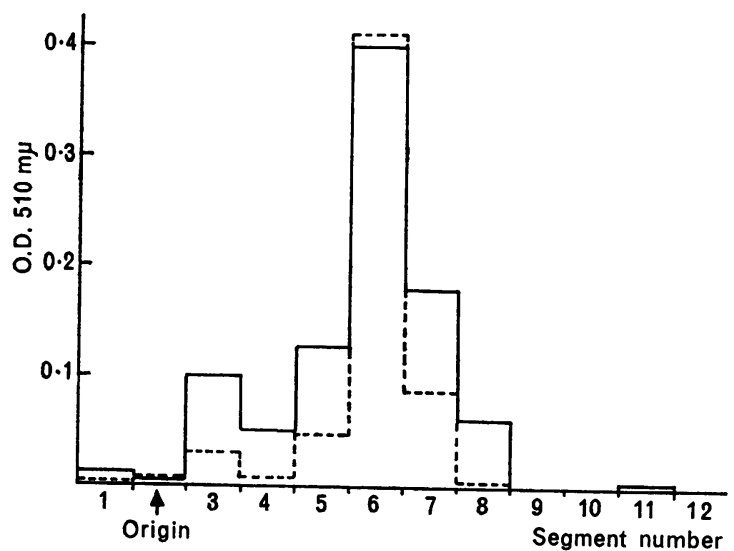

FIG. 2. Quantitative localization of serum alkaline phosphatase in two patients with bone disease.

Serum specimens from seven patients with obstructive hepatobiliary disease were found to have the major peak of activity in the $\beta$-globulin region. There was also increased activity in segments 2 and 3 (origin and $\beta$-lipoprotein regions). In all but one case, the activity in segment 2 was greater than that in segment 3 . The enzyme activity of each segment expressed as O.D. at $510 \mathrm{~m} \mu$ is shown for two patients in Figure 1.

Two peaks of enzyme activity were observed in serum from three patients with raised serum bone

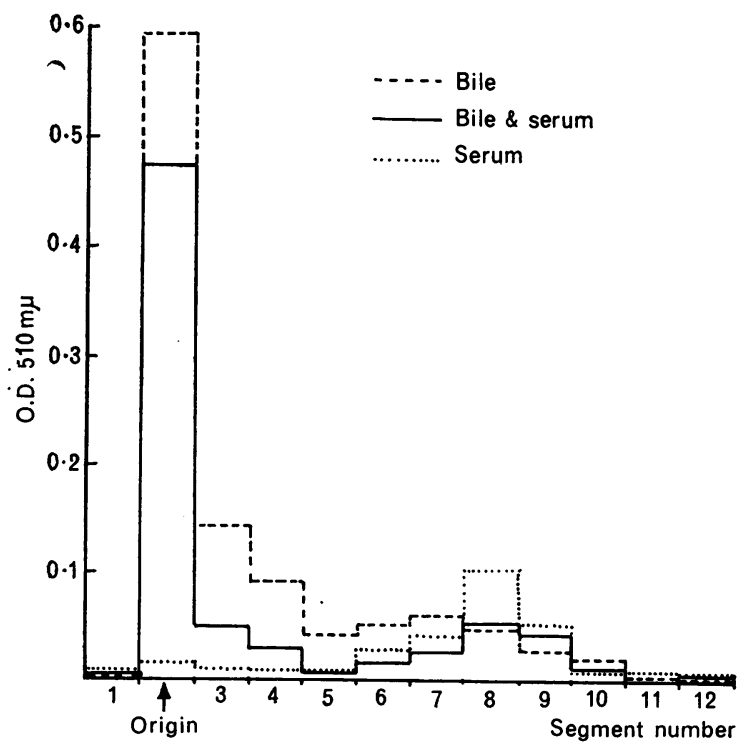

FIG. 3. Localization of alkaline phosphatase isoenzymes in bile and serum and a mixture of both. alkaline phosphatase. The major band was in position corresponding to the cathodic edge of the $\beta$-globulin region. A minor peak in segment $\overrightarrow{\overrightarrow{2}}$ corresponded to the $\beta$-lipoprotein region. The activity for two patients is shown in Figure 2.

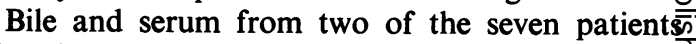
after cholecystectomy used for the qualitative method were studied by the quantitative technique. In both bile specimens segment 2 contained the greatese concentration of enzyme. The activity in the serum $P$ specimens was found to be mostly in the $\beta$-globulin $\overrightarrow{-}$ region. Electrophoresis of a mixture containing equal amounts of bile and serum from one patients gave a peak of activity at the origin and a secono peak in the $\beta$-globulin region. This is shown in Figure 3.

DETECTION OF ALKALINE PHOSPHATASE AFTER PAPERO ELECTROPHORESIS A faint band of activity was located in the $\alpha_{2}$-globulin region in normal serums and in serum from a patient with obstructive jaundice activity was observed in the $\alpha_{2}$-globulin region and at the origin. In hepatic bile activity was located at the origin.

EFFECT OF NEURAMINIDASE ON BONE AND LIVER ALKALINE PHOSPHATASE Incubation with neuraminidase caused a decrease in the mobility of the $\beta$-globulino

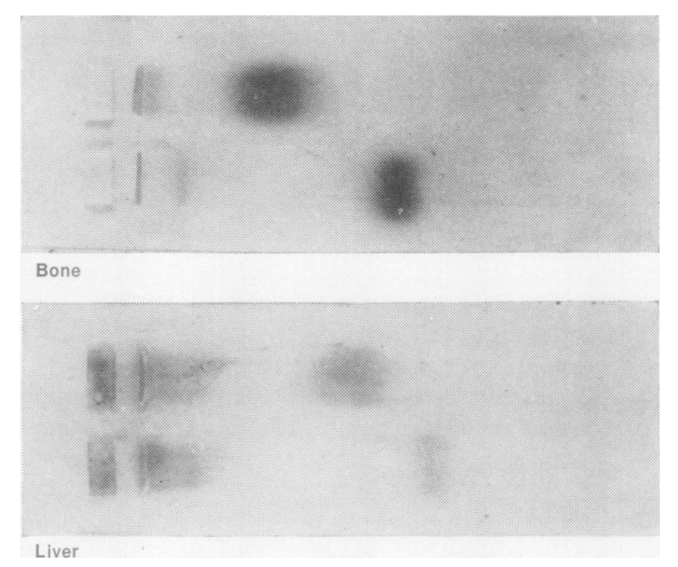

FIG. 4. Qualitative localization of alkaline phosphatase to show the effect of neuraminidase on serum alkaline phosphatase from a patient with bone disease and a patient? with liver disease.

The upper sample of both pairs was incubated with neuraminidase.

protein band, and the $\beta$-globulin and $\beta$-lipoprotein alkaline phosphatase isoenzymes in specimens of sera from a patient with Paget's disease (serum A) and å 


\section{TABLE I}

EFFECT OF NEURAMINIDASE ON THE MOBILITIES OF ALKALINE PHOSPHATASE AND $\beta$-GLOBULIN

\begin{tabular}{lll} 
Specimen & $\begin{array}{l}\text { Alkaline Phosphatase } \\
\text { Ratio T/C }\end{array}$ & $\begin{array}{l}\text { B-globulin } \\
\text { Ratio T/C }\end{array}$ \\
\hline Serum $\mathbf{A}^{1}$ & 0.53 & 0.84 \\
Serum $\mathbf{B}^{2}$ & 0.73 & 0.87
\end{tabular}

'From a patient with bone disease.

${ }^{2}$ From a patient with liver disease.

patient with obstructive liver disease (serum B). This is shown in Figure 4. The mobilities for the two sera expressed as ratios of the distance moved by the test (incubated with neuraminidase) over the distance moved by the control (incubated with inactivated neuraminidase) for the $\beta$-globulin AP and $\beta$-globulin are shown in Table $\mathrm{I}$.

Incubation of bone and liver extracts with neuraminidase also caused a decrease in the mobilities of the $\beta$-globulin alkaline phosphatase. The mobility of the bone isoenzyme was reduced to a greater extent than that of the liver isoenzyme.

\section{DISCUSSION}

Recent observations by one of us (Hill, 1965) on the changes in concentration of alkaline phosphatase in hepatic bile and serum following cholecystectomy did not support the theory of excretion of serum phosphatases in the bile but rather suggested that the alkaline phosphatase of bile is derived from the hepatobiliary system. In order to investigate further whether or not alkaline phosphatase of normal serum and of bile are identical their properties have been studied using starch gel electrophoresis, the intention being to establish the mechanism of the increased level of alkaline phosphatase in the serum in hepatobiliary disease.

The isoenzyme patterns that were observed in normal sera by the qualitative method are in agreement with other published results (Taswell and Jeffers, 1963; Chiandussi, Greene, and Sherlock, 1962; Hodson et al., 1962). Minor differences can be attributed to the use of slightly different techniques. It is probable that the $\alpha \beta$-isoenzyme found in six of the 15 normals in the current studies corresponds to the intestinal enzyme of Hodson et al. (1962). The quantitative method confirmed that the major band of alkaline phosphatase activity in normal sera is in the $\beta$-globulin region. Although this method is rather insensitive for estimating the alkaline phosphatase level of normal sera it serves as a useful check that the bands observed by the qualitative method do in fact represent sites of alkaline phosphatase activity.
The alkaline phosphatase isoenzyme patterns observed in the sera of patients with bone and liver diseases confirm the findings of previous workers and indicate that by means of starch gel electrophoresis the origin of a raised level of serum alkaline phosphatase can be stated with considerable certainty.

Although the alkaline phosphatase isoenzyme patterns of sera from patients with bone and liver diseases are well documented there have been few studies on those patterns in normal human hepatic bile. To understand more fully the rationale behind the use of alkaline phosphatase as a liver function test it seemed important to observe simultaneously both the serum and hepatic bile alkaline phosphatase isoenzyme patterns. This was accomplished using serum and hepatic bile from seven patients who had undergone cholecystectomy for cholelithiasis and were not suffering from any liver disease. Specimens were collected between the fifth and 13th days postoperatively. The major band of alkaline phosphatase activity in the serum from each patient was in the $\beta$-globulin region whereas in the bile specimens from these patients the major band of activity in each case was in the $\gamma$-globulin region. The $\beta$-globulin isoenzyme was present in only one specimen and then only as a faint band of activity by the qualitative method. In three cases the $\gamma$-globulin isoenzyme was the only band detected. The quantitative method of locating alkaline phosphatase confirmed that the major band of activity in bile has a mobility similar to that of the serum $\gamma$-globulins.

That the difference in mobility between the major serum and bile isoenzymes is not merely due to a difference in the protein concentrations of the samples was demonstrated by locating the alkaline phosphatase activity by the quantitative method after simultaneous electrophoresis of $20 \mu \mathrm{l}$. bile, $20 \mu \mathrm{l}$. serum, and $20 \mu \mathrm{l}$. of a mixture of equal volumes of bile and serum. The two bands of enzyme activity remained distinct in the mixture (Fig. 3).

From these studies it is evident that the normal alkaline phosphatase isoenzyme of hepatic bile migrates to a position corresponding to the serum $\gamma$-globulins. It is also evident that the normal serum and normal hepatic bile alkaline phosphatase do not have the same electrophoretic mobilities. These observations confirm the results of a recent paper in which bile was obtained from human gall bladders (Pope and Cooperband, 1966).

The results from the paper electrophoresis of serum and bile indicate that the differences in the mobilities of the bile and serum isoenzymes on starch gel are primarily a reflection of their differing negative charges, rather than differences in molecular size, since their electrophoretic mobilities are 
essentially the same on both media. This is consistent with the findings of Pope and Cooperband (1966) that by ultracentrifugation the molecular sizes of the serum and bile isoenzymes are similar.

A consistent finding in the sera of patients with liver disease is an elevated $\beta$-globulin alkaline phosphatase isoenzyme, and some authors have suggested that this isoenzyme originates from bone (Kowlessar et al., 1959), that is, the high levels of this isoenzyme seen in obstructive jaundice represent failure of the liver to excrete the bone enzyme from the serum into the bile. By vertical starch gel electrophoresis, Hodson et al. (1962) were able to show that the $\beta$-globulin isoenzymes of liver and bone diseases had slightly different mobilities, which is evidence against this theory. Further evidence is provided by the results presented in this paper on the differing effects of neuraminidase on the $\beta$ globulin isoenzyme of alkaline phosphatase in the serum of a patient with bone disease and a patient with obstructive liver disease. It has been shown that the mobility of the $\beta$-globulin isoenzyme of liver extracts is reduced by treatment with neuraminidase (Moss, Eaton, Smith, and Whitby, 1966) and the results presented here confirm this finding and also show that the mobility of the bone $\beta$-globulin isoenzyme is reduced to an even greater extent. The observations on the serum isoenzymes were confirmed using bone and liver extracts. The mobility of the $\beta$-globulin protein band was also reduced by this treatment but to a lesser degree and to the same extent in both sera.

These results provide clear evidence that the $\beta$-globulin isoenzyme, which is elevated in the sera of patients with liver disease, is not identical with the bone $\beta$-globulin isoenzyme, and therefore it is suggested that the increased level does not arise due to failure of the liver to excrete the bone isoenzyme. An alternative explanation based on the evidence discussed in this paper, which accounts for the raised level of alkaline phosphatase in liver and bone diseases and for the presence of the enzyme in bile, is now presented.

In the normal child the variations in serum alkaline phosphatase with age have been shown to be closely correlated with the rate of growth (Clark and Beck, 1950); also the starch gel serum alkaline phosphatase isoenzyme patterns of normal children are identical with those from adults with Paget's disease. It may therefore be assumed that in children the major part of serum alkaline phosphatase is derived from the osteoblasts.

Opinion is divided as to the origin of serum alkaline phosphatase in the adult; however, a considerable proportion is apparently of hepatic origin, the skeletal system and intestines also being contributory sources (Schlamowitz, 1958; Hodson $\stackrel{0}{\frac{0}{2}}$ et al., 1962; Taswell and Jeffers, 1963; Estborn, 을 1964). Since alkaline phosphatase is present in con- $\Rightarrow$ siderable amounts at the sinusoidal surface of the liver cell (Wachstein and Meisel, 1958) it is suggested? that this is the origin of the hepatic isoenzyme of $\frac{}{\bar{N}}$ normal serum.

The serum levels of the enzyme in children and $\stackrel{\mathbb{}}{\varrho}$ adults are maintained at normal by processes, the precise nature of which are unknown, but which $\vec{\circ}$ probably involve inactivation of the enzyme and incorporation into the body protein pool. It has $\vec{\omega}$ been shown in dogs that the rate of disappearance? of injected alkaline phosphatase is similar to thato of intravenously injected isotopically labelled plasma i protein fractions (Cantarow and Miller, 1948). There is no direct evidence to show that alkaline phos- $\mathrm{S}$ phatase passes from the serum through the hepatic + cell into the bile, and indeed to postulate this theory one has to assume that a protein, with a molecular ${ }_{C}$ weight of about 100,000 (Engstrom, 1961), can readily pass through the hepatic cell membrane both at the sinusoidal and canalicular surfaces. $\mathscr{\leftrightarrow}$ Further evidence against this theory is that infused. placental alkaline phosphatase is removed from the circulation at similar rates in normal subjects and in patients with biliary obstruction (Clubb, Neale, and Posen, 1965).

In diseases in which increased osteoblastic $\frac{\circ}{\square}$ activity accounts for the raised serum level it can $\overrightarrow{\vec{F}}$ be seen that the serum level will increase because 3 the rate of release of the enzyme into the serum will? now exceed its rate of inactivation.

In parenchymal liver disease it has been shown that the predominant increase in the serum alkaline? phosphatase is in the $\beta$-globulin isoenzyme, with 3 much slighter increases in the $\gamma$-globulin isoenzyme compared with the pattern seen in obstructive $\mathrm{O}$ hepatobiliary disease (Hodson et al., 1962; Taswell and Jeffers, 1963). Chiandussi et al. (1962) observed음 an increase solely in the $\beta$-globulin band in 10 cases $\frac{?}{0}$ of infective hepatitis. This is consistent with liver cell damage causing release of the sinusoidal ${ }_{\mathscr{O}}$ isoenzyme into the blood, which, as suggested earlier, migrates in the $\beta$-globulin region. In the early stages of hepatitis, parenchymal cell damage $\omega$ occurs with little biliary obstruction and therefore? reflux of bile from the canaliculi with the consequent appearance in the serum of the $\gamma$-globulin isoenzyme does not occur to any great extent.

In extrahepatic obstructive jaundice, causing obstruction to the passage of bile through the extraheptic bile ducts, bile stasis will occur which? will eventually lead to reflux into the blood of bileo containing the $\gamma$-globulin alkaline phosphatase isoenzyme which has been shown in these studies 
to be the normal alkaline phosphatase of bile. The $\gamma$-globulin isoenzyme is then increased in the serum as well as the $\beta$-globulin isoenzyme from the damaged cells, as has been observed in the starch gel studies. The $\gamma$-globulin isoenzyme is apparently of bile duct or canalicular origin, possibly from the microvilli of the canalicular surface of the hepatic cell. The intestinal isoenzyme band in two cases of obstructive jaundice was not observed to be increased above that seen in normals and suggests that this isoenzyme was still being eliminated from the serum by the normal method, despite the blockage to the flow of bile, that is to say, by a mechanism not involving excretion by the liver.

In intrahepatic obstruction, for example due to secondary tumour deposits, the flow of bile may be impeded from only small areas of the liver. In these areas, bile flow will be impeded and reflux of bile, containing bilirubin and the $\gamma$-globulin isoenzyme of alkaline phosphatase will occur proximal to the tumour metastases into the sinusoids. The bilirubin will be excreted into the bile by another area of liver or excreted by the kidney; however alkaline phosphatase which is not excreted by the liver or kidney will remain in the circulation to be inactivated, as postulated earlier. Thus serum alkaline phosphatase levels will be elevated, although hyperbilirubinaemia will not occur because there is sufficient reserve functional tissue in the liver (Popper and Szanto, 1956) to handle the increased bilirubin load put upon it. Serum alkaline phosphatase is thus more sensitive as a test of intrahepatic obstruction than is bilirubin and bromsulphthalein
(Gibbons, 1957), since these latter compounds will be removed from the serum by the remaining functioning liver tissue. Theoretically obstruction of one of the main hepatic ducts could lead to a similar picture. The remaining half of the biliary system should be sufficient to remove all the bilirubin, but much larger increases in serum alkaline phosphatase will occur due to regurgitation of bile from such a wide area of the liver.

\section{REFERENCES}

Cantarow, A., and Miller, L. L. (1948). Amer. J. Physiol., 153, 444. Chiandussi, L., Greene, S. F., and Sherlock, S. (1962). Clin. Sci., 22, 425.

Clark, L. C., Jr., and Beck, E. (1950). J. Pediat., 36, 335.

Clubb, J. S., Neale, F. C., and Posen, S. (1965). J. Lab. clin. Med., $66,493$.

Engstrom, L. (1961). Biochim. biophys. Acta (Amst.), 52, 36.

Estborn, B. (1964). Z. klin. Chem., 2, 53.

Gibbons, T. B. (1957). J. Amer. med. Ass., 164, 22.

Gutman, A. B. (1959). Amer. J. Med., 27, 875.

Hill, P. G. (1965). M.Sc. Thesis, University of Birmingham.

Hodson, A. W., Latner, A. L., and Raine, L. (1962). Clin. chim. Acta, 7, 255.

Kind, S. S. (1958). Nature (Lond.), 182, 1372.

Kowlessar, O. D., Pert, J. H., Haeffner, L. J., and Sleisenger, M. H. (1959). Proc. Soc. exp. Biol. (N.Y.), 100, 191.

Moss, D. W., Eaton, R. H., Smith, J. K., and Whitby, L. G. (1966). Biochem. J., 98, 32C.

Pope, C. E., II, and Cooperband, S. R. (1966). Gastroenterology, $50,631$.

Popper, H., and Szanto, P. B. (1956). Ibid., 31, 683.

Robinson, J. C., and Pierce, J. E. (1964). Nature (Lond.), 204, 472.

Roos, K. (1963) Scand. J. clin. Lab. Invest., 15, suppl. 69, 233.

Schlamowitz, M. (1958). Ann. N.Y. Acad. Sci., 75, 373.

Smith, I. (1960). Chromatographic and Electrophoretic Techniques, Vol. II. Heinemann, London.

Smithies, O. (1955). Biochem. J., 61, 629.

Taswell, H. F., and Jeffers, D. M. (1963). Amer. J. clin. Path., 40, 349.

Wachstein, M., and Meisel, E. (1958) Arch. Path., 65. 449.

Wilkinson, J. H. (1962). An Introduction to Diagnostic Enzymology. Arnold, London. 